\title{
Biventricular function in Friedreich's ataxia: a radionuclide angiographic study
}

\author{
B PALAGI, * R PICOZZI, * F CASAZZA, $\dagger$ M POSSA, $\ddagger$ G MAGRI, \\ O ZOCCARATO, * E GRAZIANO, * F FERRARI, $\dagger$ M MORPURGO $\dagger$ \\ From the ${ }^{\star}$ Division of Nuclear Medicine, Hospital of Saronno, Varese; †Department of Cardiology, San Carlo \\ Hospital, and $\ddagger$ Division of Nuclear Medicine, Cá Granda Hospital, Niguarda, Milan, Italy
}

SUMMARY The systolic and diastolic function of both ventricles was assessed by radionuclide angiography in 21 patients with Friedreich's ataxia and hypertrophic cardiomyopathy. The indices of systolic function of the two ventricles and those of diastolic function of the right ventricle were generally normal. But in patients with Friedreich's ataxia the time to peak filling rate divided by the diastolic time of the left ventricle was significantly larger than normal. The increase correlated with the heart rate $(r=0.79)$ and this suggests an alteration in the timing of ventricle filling that is more evident at high heart rates. Movement of the left ventricle was little impaired; however, in $48 \%$ of the patients with Friedreich's ataxia the right ventricle showed evidence of hypokinetic segments.

Because there is a tendency for congestive heart failure to develop in patients with Friedreich's ataxia, this hypokinesis of the right ventricle should be monitored at follow up.

In earlier studies of left ventricular function in patients with Friedreich's ataxia we found: $(a)$ a tendency for the pre-ejection period of the left ventricle to increase and for the ejection period to shorten, especially in patients with increased heart rates $^{1}$; and (b) a significant reduction in left ventricular fractional shortening and ejection fraction of the left ventricle. ${ }^{2}$ St John Sutton et al found that the diastolic function of the left ventricle, assessed by computerised $M$ mode echocardiography, was abnormal in seven patients with Friedreich's ataxia. ${ }^{3}$ Others reported a significant reduction in the thinning rates of the left ventricular posterior wall and interventricular septum in 13 patients with Friedreich's ataxia. ${ }^{4}$

The only scintigraphic studies of left ventricular function in patients with Friedreich's ataxia are those of Pentland and Fox ${ }^{5}$ and Therriault et $a l^{6}$ in which the ejection fraction was normal in most cases. We do not know of any radionuclide studies of the diastolic function of the left ventricle and the overall function of the right ventricle in this disease. We have assessed the function of both ventricles by radionuclide angiography in a group of patients with Friedreich's ataxia.

Requests for reprints to Professor M Morpurgo, Via Boccaccio 24, 20123 Milan, Italy.

Accepted for publication 1 December 1987

\section{Patients and method}

We obtained gated blood pool scintigrams from 21 patients (12 male patients and nine female patients; aged from 11 to 34, mean (SD) $19.5(6.2)$ ) in whom Friedreich's ataxia was diagnosed by Geoffroy's criteria $^{7}$ and in whom there was echocardiographic evidence of left ventricular hypertrophy. Neuromuscular impairment ${ }^{8}$ was slight in six patients, moderately severe in three, and severe in 12 . None had any signs of heart failure. The echocardiographic findings obtained in these cases (table 1) were compared with reference values from 50 healthy controls.

For the scintigraphic study we used a control group of eight healthy volunteers (five male and three female, aged from 12 to 38 (mean (SD) $21.5(5.0)$ ). Gated radionuclide angiography was carried out after in vivo labelling of the erythrocytes with stannous diethylenetriamine pentaacetic acid and intravenous injection of $750 \mathrm{MBq}$ of technetium$99 \mathrm{~m}$ pertechnetate. Ten minutes after injection of the tracer each patient was examined in the supine position with a large-field Anger scintillation camera equipped with a general purpose low energy parallel hold collimator connected on line to a minicomputer. A computer program gated to the electrocardiogram (SYMA, Elscint) collected and organised scintigraphic data into a series of 24 frames on a matrix of $64 \times$ 
Table 1 Statistical comparison (Student's $t$ test) of echocardiographic variables in healthy controls and in patients with Friedreich's ataxia

\begin{tabular}{|c|c|c|c|}
\hline & $\begin{array}{l}50 \text { healthy } \\
\text { controls }\end{array}$ & $\begin{array}{l}21 \text { cases of } \\
\text { Friedreich's } \\
\text { ataxia }\end{array}$ & $p$ \\
\hline $\begin{array}{l}\text { Age } \\
\text { Body surface area } \\
\left(\mathbf{m}^{2}\right)\end{array}$ & $\begin{array}{c}23 \cdot 8(7 \cdot 1) \\
1 \cdot 4(0 \cdot 20)\end{array}$ & $\begin{array}{c}19.5(6 \cdot 2) \\
1.5(0 \cdot 15)\end{array}$ & $\begin{array}{l}\text { NS } \\
\text { NS }\end{array}$ \\
\hline $\begin{array}{l}\text { LVEDD (mm) } \\
\text { FS \% } \\
\text { IVSTh (mm) } \\
\text { LVPWTh (mm) } \\
\text { RWTh } \\
\text { LV mass index }\end{array}$ & $\begin{array}{l}46(3.6) \\
39(4.9) \\
7 \cdot 3(1 \cdot 3) \\
6.9(1 \cdot 1) \\
0.310(0.05)\end{array}$ & $\begin{array}{l}38(5 \cdot 3) \\
36(8 \cdot 3) \\
12 \cdot 3(4 \cdot 1) \\
10 \cdot 8(1 \cdot 5) \\
0 \cdot 613(0 \cdot 11)\end{array}$ & $\begin{array}{l}<0.01 \\
<0.05 \\
<0.01 \\
<0.01 \\
<0.01\end{array}$ \\
\hline $\begin{array}{l}\left(\mathrm{g} / \mathrm{m}^{2}\right) \\
\text { IVSTh:LVP- } \\
\text { WTh }\end{array}$ & $\begin{array}{l}73(16) \\
1 \cdot 1(0 \cdot 15)\end{array}$ & $\begin{array}{l}121(50) \\
1 \cdot 1(0 \cdot 33)\end{array}$ & $\begin{array}{l}<0.01 \\
\text { NS }\end{array}$ \\
\hline
\end{tabular}

LVEDD, left ventricular end diastolic diameter; FS $\%$, left ventricular fractional shortening; IVSTh, interventricular septum thickness; LVPWTh, left ventricular posterior wall thickness; $R W T h$, relative wall thickness; LV mass index, left ventricular mass index.

64 pixels that spanned the average cardiac cycle. The method has been validated for the assessment of the ejection fraction of both ventricles. ${ }^{10}$

We studied each patient in a left anterior oblique $35-45^{\circ}$ projection and in a projection obtained by turning the crystal $40^{\circ}$ counterclockwise. Twenty four points that were representative of the volume curve for each ventricle were transferred to a memory of a desk computer (Hewlett-Packard 85) and fitted with a Fourier series; the first four harmonics were usually retained. ${ }^{11}$ The function obtained was differentiated to compute (fig 1) peak filling rate and peak ejection rate; the time to peak filling rate and time to peak ejection rate divided by the length of diastole and systole respectively were also calculated. Furthermore, we calculated the percentage of the stroke volume filled at the end of the rapid filling period and the percentage of the stroke volume filled at the end of atrial systole. We identified the end of the rapid filling period as point $\mathrm{C}$ on the derived curve. ${ }^{12}$ The percentage stroke volume filled at the end of atrial systole was calculated as the difference between total stroke volume and the fraction filled at the end of the rapid filling period; the contribution of diastasis to the slow filling was discounted.

Regional wall motion was assessed by examining the parametric images obtained by Fourier analysis of scintigraphic data. ${ }^{9}$ Regional right ventricular wall motion was analysed by end diastolic and end systolic isocontours. On the right ventricular outline we identified the anterior and inferior walls. On the left ventricular outline we defined the septal, apical, inferior, and posterolateral segments in the left anterior oblique projection, and the apical and inferior segments in the anterior projection.

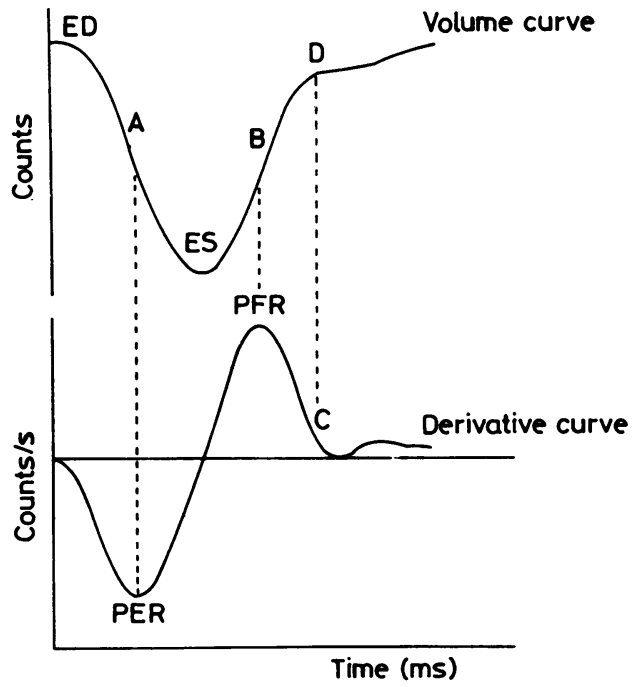

Fig 1 The upper curve is a left ventricular volume curve obtained by equilibrium gated radionuclide angiography. The lower curve is the first derivative of the left ventricular volume curve. Point $A$ is the volume at which the peak ejection rate (PER) occurs. Point $B$ is the volume at which the peak filling rate (PFR) occurs. Point $C$ is the point after which $20 \%$ of the PFR occurs and represents the end of the rapid filling period. Point $D$ on the volume curve represents the corresponding volume that marks the end of the rapid filling period. ED, end diastole; $E S$, end systole.

Table 2 Radionuclide variables describing left ventricular function (mean (SD))

\begin{tabular}{|c|c|c|c|}
\hline & $\begin{array}{l}\text { Healthy } \\
\text { volunteers } \\
(n=8)\end{array}$ & $\begin{array}{l}\text { Friedreich's } \\
\text { ataxia } \\
(n=21)\end{array}$ & $p$ \\
\hline \multirow{6}{*}{$\begin{array}{l}\text { Heart rate (beats/ } \\
\text { min) } \\
\text { Ejection fraction } \\
(\%) \\
\text { Peak ejection rate } \\
\text { (EDV/s) } \\
\text { TPER/ST } \\
\text { ST/RR } \\
\text { Peak filling rate } \\
\text { (EDV/s) } \\
\text { TPFR/DT } \\
\% \text { SV-RFP } \\
\% \text { SV-AS }\end{array}$} & $64(8)$ & $77(12)$ & $<0.02$ \\
\hline & $71(5)$ & $75(12)$ & NS \\
\hline & $-3.30(0.38)$ & $-3.58(0.74)$ & NS \\
\hline & $0.56(0.04)$ & $0.55(0.05)$ & NS \\
\hline & $0.40(0.03)$ & $0.41(0.06)$ & NS \\
\hline & $\begin{array}{l}3.55(0.32) \\
0.24(0.06) \\
88(3) \\
12(3)\end{array}$ & $\begin{array}{l}3.35(0.73) \\
0.32(0.08) \\
89(7) \\
11(7)\end{array}$ & $\begin{array}{l}\text { NS } \\
<0.025 \\
\text { NS } \\
\text { NS }\end{array}$ \\
\hline
\end{tabular}

TPER/ST, time to peak ejection rate/systolic time; TPFR/DT, time to peak filling rate/diastolic time; \% SV-RFP, percentage stroke volume filled at the end of the rapid filling period; \% SV-AS, percentage stroke volume filled during atrial systole; $\mathrm{ST}$, systolic time; RR, RR interval; EDV/s, end diastolic volume per second.

STATISTICAL ANALYSIS

All data are expressed as mean (1SD) with the $95 \%$ confidence limit as the range of normal values. All comparisons between patients and healthy controls were made by Student's $t$ test and Bartlett's test was used to assess the homogeneousness of variances in 
the two groups; linear regression variables were calculated by the method of least squares.

\section{Results}

\section{LEFT VENTRICULAR FUNCTION}

Table 2 shows the data on left ventricular function. Indices of systolic function were usually normal, although the ejection fraction was greater than normal in nine patients and reduced $(0 \cdot 40)$ in one. The ratio of time to peak filling rate to diastolic time was higher in patients (mean (SD) $0.32(0.08)$ ) than in normal controls (mean (SD) $0.24(0.06)$ ). The increase correlated with increasing heart rate $(r=$ 0.79 ); there was a $24 \%$ increase for each 10 beat/ minute increase in heart rate (fig 2 ).

\section{RIGHT VENTRICULAR FUNCTION}

The data on right ventricular function in our patients (table 3) were not statistically significantly different from normal values.

\section{WALL MOTION ABNORMALITIES}

The frequency of wall motion abnormalities was different in the left and right ventricles (table 4). The left ventricle showed hypokinetic segments in three $(14 \%)$ of our 21 patients, with $8(7.6 \%)$ of 105 segments being affected. The right ventricle showed wall motion abnormalities in $10(48 \%)$ patients, with $13(31 \%)$ of 42 segments being hypokinetic. The alterations of right ventricle wall movement, however, were never severe enough to produce a statistically significant reduction in the ejection fraction. There were no akinetic or dyskinetic segments in either ventricle in any of our patients.

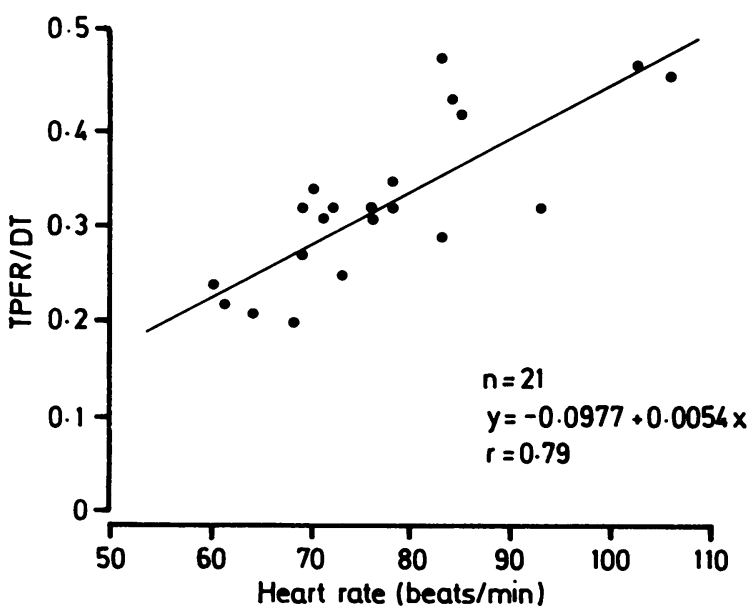

Fig 2 Linear regression between heart rate and left ventricular time to peak filling rate divided by the diastolic time ( LVTPFR/DT).
Table 3 Radionuclide variables describing right ventricular function

\begin{tabular}{llll}
\hline & $\begin{array}{l}\text { Healthy } \\
\text { volunteers } \\
(n=8)\end{array}$ & $\begin{array}{l}\text { Friedreich's } \\
\text { ataxia } \\
(n=21)\end{array}$ & $p$ \\
\hline $\begin{array}{l}\text { Heart rate (beats/ } \\
\text { min) }\end{array}$ & $64(8)$ & $77(12)$ & $<0.02$ \\
$\begin{array}{l}\text { Ejection fraction } \\
(\%)\end{array}$ & $58(8)$ & $54(13)$ & NS \\
$\begin{array}{l}\text { Peak ejection rate } \\
\text { (EDV/s) }\end{array}$ & $-2.47(0.46)$ & $-2.25(0.59)$ & NS \\
$\begin{array}{l}\text { TPER/ST } \\
\begin{array}{l}\text { Peak filling rate } \\
(\text { EDV/s) }\end{array}\end{array}$ & $0.57(0.15)$ & $0.54(0.15)$ & NS \\
\begin{tabular}{l} 
TPFR/DT \\
\hline
\end{tabular} & $0.73(0.49)$ & $2.30(0.59)$ & NS \\
\hline
\end{tabular}

TPER/ST, time to peak ejection rate/systolic time; TPFR/DT, time to peak filling rate/diastolic time; EDV/s, end diastolic volume per second.

Table 4 Frequency of regional wall motion abnormalities of the left and right ventricles in 21 patients with Friedreich's ataxia

\begin{tabular}{llll}
\hline & $\begin{array}{l}\text { No of patients } \\
\text { with hypokinesis } \\
\left({ }_{0}\right)\end{array}$ & $\begin{array}{l}\text { Total segments } \\
\text { examined }\end{array}$ & $\begin{array}{l}\text { Hypokinetic } \\
\text { segments }\end{array}$ \\
\hline $\begin{array}{l}\text { Left ventricle } \\
\text { Right ventricle }\end{array}$ & $\begin{array}{r}3(14) \\
10(48)\end{array}$ & $\begin{array}{l}105 \\
42\end{array}$ & $\begin{array}{l}8(8)^{\star} \\
13(31) \dagger\end{array}$ \\
\hline
\end{tabular}

*Septal 2, apical 1, anterolateral, 1, posterolateral 2, inferior 2. +Anterior 10 , inferior 3.

\section{Discussion}

In our series of patients with Friedreich's ataxia and hypertrophic cardiomyopathy, radionuclide angiocardiography of the left ventricle showed that overall systolic function was generally normal, as did Pentland and Fox (in 12 similar patients) ${ }^{5}$ and St John Sutton et al (in seven patients examined by computerised $\mathbf{M}$ mode echocardiography). ${ }^{3}$ The slight difference seen in our cases between the data obtained by $\mathbf{M}$ mode echocardiography and radionuclide angiography is not surprising in view of the different methods of calculating the ejection fraction. The radioisotope method is better, especially in patients like ours in whom movement of the interventricular septum and posterior wall of the left ventricle is abnormal.

Only one of the indices that we investigated (table 2) was significantly different in the patients with Friedreich's ataxia. This was the ratio of time to peak filling rate/diastolic-time interval, which was increased $(p<0.02)$; this was an average increase of $24 \%$ for each heart rate increase of 10 beats/minute $(\mathrm{r}=0.79)$. This suggests that in patients with Friedreich's ataxia complicated by hypertrophic cardiomyopathy the timing of left ventricular filling 
is abnormal, with the defect being more evident at higher heart rates. The left ventricular peak filling rate was generally normal, and this result accords with the computerised echocardiographic study of St John Sutton et al in a series of seven cases ${ }^{3}$ and with that of Casazza et al who studied 13 patients. ${ }^{4}$

Echocardiographic (especially $M$ mode) assessment of the right ventricle is difficult; none the less, there are only a few angiographic studies, ${ }^{13-15}$ generally of single cases of Friedreich's ataxia, showing hypertrophy of the right ventricle, sometimes associated with dynamic infundibular stenosis. Our radionuclide study showed that the systolic and diastolic function of the right ventricle is essentially normal in such patients despite the relatively frequent detection of regional hypokinesia, usually of the anterior wall. With allowance for possible diagnostic errors caused by the difficulty of distinguishing the free wall from the outflow tract of the right ventricle, this finding may be clinically important if it accounts for the evolution of congestive heart failure that complicates certain cases of Friedreich's ataxia. ${ }^{16}$ It will be interesting to follow up our patients to see whether alterations in the movement of the right ventricle are associated with the development of congestive heart failure.

\section{References}

1 Beulcke G, Casaccia M, Finardi G, Morpurgo $M$, Rampulla C, Venco A. L'appareil cardiovasculaire dans les hérédodégé-néréscences spino-cérébelleuses. Arch Mal Coeur 1973;66:725-37.

2 Beulcke G, Bottoni R, Casazza F, Uziel G, Morpurgo $M$. Aspects cardiologiques de l'hérédoataxie du type Friedreich. Arch Mal Coeur 1982;75:583-92.

3 St John Sutton MG, Olukotun AY, Tajik AJ, Lovett JL, Giuliani ER. Left ventricular function in Friedreich's ataxia: an echocardiographic study. $\mathrm{Br} J$ Heart 1980;44:309-16.

4 Casazza F, Ferrari F, Finocchiaro G, et al. Echocar- diographic evaluation of verapamil in Friedreich's ataxia. Br Heart J 1986;55:400-4.

5 Pentland B, Fox KAA. The heart in Friedreich's ataxia. J Neurol Neurosurg Psychiatry 1983;46:1138-42.

6 Therriault L, Lamoreux G, Côté M, Plourde G, Lemieux B. The cardiomyopathy in Friedreich's ataxia: isotopic ventriculography and myocardial imaging with thallium-201. Can J Neurol Sci 1984;11:588-91.

7 Geoffroy G, Barbeau A, Breton G, et al. Clinical description and roentgenologic evolution of patients with Friedreich's ataxia. Can J Neurol Sci 1976; 3:279-86.

8 Côté M, Davignon A, Pecko Drouin K, et al. Cardiological signs and symptoms in Friedreich's ataxia. Can J Neurol Sci 1976;3:319-21.

9 Picozzi R, Tarolo GL, Ricci A, Palagi B, Zatta G, Baroffio $R$. Clinical value of phase and amplitude images and left ventricle time-activity curves in assessing patients with acute myocardial infarction. Eur J Nucl Med 1984;9:6-11.

10 Palagi B, Baroffio R, Picozzi R, et al. Radionuclide assessment of right ventricular involvement in inferior acute myocardial infarction: clinical correlations and in-hospital follow up. Eur $J$ Nucl Med 1985;10:235-40.

11 Miller TR, Goldman KJ, Sampathkumaran KS, Biello DR, Ludbrook PA, Sobel BE. Analysis of cardiac diastolic function: application in coronary artery disease. J Nucl Med 1983;24:2-7.

12 Gibson DG, Brown D. Measurement of instantaneous left ventricular dimension and filling rate in man, using echocardiography. Br Heart J 1973;35:1141-9.

13 Thoren C. Cardiomyopathy in Friedreich's ataxia with studies of cardiovascular and respiratory function. Acta Paediatr Scand [Suppl] 1964;153:1-136.

14 Gach JV, Andriange M, Frank G. Hypertrophic obstructive cardiomyopathy and Friedreich's ataxia: report of a case and review of literature. Am J Cardiol $1971 ; 27: 436-41$.

15 Ruschhaupt DG, Thilenius OG, Cassels DE. Friedreich's ataxia associated with idiopathic hypertrophic subaortic stenosis. Am Heart J 1972; 84:95-102.

16 Berg RA, Kaplan AM, Jarrett PB, Molthan ME. Friedreich's ataxia with acute cardiomyopathy. Am J Dis Child 1980;134:390-3. 